\title{
Personalized physiology-guided resuscitation in highly monitored patients with cardiac arrest-the PERSEUS resuscitation protocol
}

\author{
Athanasios Chalkias $^{1,2,3}$ (D) Eleni Arnaoutoglou ${ }^{1} \cdot$ Theodoros Xanthos $^{4}$ \\ Published online: 11 February 2019 \\ (C) Springer Science+Business Media, LLC, part of Springer Nature 2019
}

\begin{abstract}
Resuscitation guidelines remain uniform across all cardiac arrest patients, focusing on the delivery of chest compressions to a standardized rate and depth and algorithmic vasopressor dosing. However, individualizing resuscitation to the appropriate hemodynamic and ventilatory goals rather than a standard "one-size-fits-all" treatment seems a promising new therapeutic strategy. In this article, we present a new physiology-guided treatment strategy to titrate the resuscitation efforts to patient's physiologic response after cardiac arrest. This approach can be applied during resuscitation attempts in highly monitored patients, such as those in the operating room or the intensive care unit, and could serve as a method for improving tissue perfusion and oxygenation while decreasing post-resuscitation adverse effects.
\end{abstract}

Keywords Resuscitation $\cdot$ Physiology-guided treatment $\cdot$ Pathophysiology $\cdot$ Cardiac arrest $\cdot$ Monitoring

\section{Introduction}

Since 2000, resuscitation guidelines remain uniform across all cardiac arrest patients, focusing on the delivery of chest compressions to a standardized rate and depth and algorithmic vasopressor dosing [1]. The widespread implementation of this algorithmic approach was responsible for the impressive improvements in survival in recent years. However, evidence has shown that intra-arrest optimization of coronary perfusion pressure (CPP), diastolic arterial pressure (DAP), and/or endtidal carbon dioxide $\left(\mathrm{ETCO}_{2}\right)$ may improve the quality of cardiopulmonary resuscitation (CPR) and outcome [2-4]. This is feasible in highly monitored settings, such as the operating room or the intensive care unit, in which titration of resuscitation efforts to an individual patient's physiologic response may improve survival while decreasing postresuscitation adverse effects [5]. In this context, several

Athanasios Chalkias

thanoschalkias@yahoo.gr

1 Faculty of Medicine, Department of Anesthesiology, University of Thessaly, Larisa, Greece

2 Hellenic Society of Cardiopulmonary Resuscitation, Athens, Greece

3 Department of Anesthesiology, University Hospital of Larisa, C' Wing, 2nd Floor, Mezourlo, PO Box 1425, 41110 Larisa, Greece

4 School of Medicine, European University Cyprus, Nicosia, Cyprus studies have demonstrated the efficacy of hemodynamicdirected CPR for improving rates of survival with favorable neurologic outcomes $[6,7]$.

Research on resuscitation made early gains, but recent progress has been slow due to the dispersion of the researchers to other aspects than elucidating the physiology and pathophysiology of cardiac arrest and resuscitation. Addressing the unique needs of our patients by assessing their individual response in real time to interventions and titrating our therapies seems the only way for improving outcome and pursuing methods of CPR that are based on patient physiology should be the "holy grail" of resuscitation science.

Although the concept of goal-directed hemodynamic optimization as a treatment strategy to improve clinical outcome in critically ill patients has been tested since the 1980 s, no human study has established that prospectively targeting hemodynamics during CPR improves outcomes until now [8]. Nevertheless, individualizing resuscitation to the appropriate hemodynamic and ventilatory goals rather than a standard "one-size-fits-all" treatment seems a promising new therapeutic strategy that can be applied during resuscitation attempts in highly monitored patients.

The PERSEUS protocol is a new approach to the resuscitation of highly monitored patients with cardiac arrest. It has been developed based on our experience and the observation that the most important determinant of survival is the optimization of all the available physiological parameters and the full exploitation of both the "cardiac pump" and "thoracic pump." 
The aim of this review is to present the PERSEUS protocol and the related rationale and methodology for physiologyguided CPR.

\section{Physiological and pathophysiological aspects of cardiac arrest}

\section{Cardiac arrest interval}

Immediately after the abrupt loss of effective blood flow, the hypotension-induced baroreflex withdrawal with the net increase in the vascular resistance maintains an impaired antegrade and pulmonary blood flow [9]. The systemic and pulmonary blood flow continue for at least 30-60 s, until the pressure gradient between the aorta and the right side of the heart, as well as between the pulmonary artery and the left atrium, has been completely dissipated, resulting in a rapid increase in the volume of the right ventricle and the extrapericardial component of the pulmonary veins. When arterial and systemic venous pressures reach equilibrium, the mean systemic filling pressure (Pmsf) is approximately 6$12 \mathrm{mmHg}$ [10]. The coronary blood flow declines to zero, but CPP remains positive because of the retrograde coronary flow. However, this diminishes the removal of norepinephrine from the interstitial spaces, which together with the formation of cardiac edema prolongs vasoconstriction and enhances myocardial hypoperfusion and hypoxia.

At the same time, cerebral perfusion decreases while the damage of fatty acids of the neuronal cell membrane by reactive oxygen species leads to a progressive increase in membrane permeability and severe derangements of intracellular electrolytes, resulting in cell swelling and brain edema formation [10]. This, together with venous congestion, increases intracranial pressure (ICP) and damages the neuropil and synaptic structures and/or contacts.

\section{Cardiopulmonary resuscitation}

Myocardial blood flow is a major determinant of resuscitation success. With the onset of CPR, chest compressions result in forward blood, but even during optimal CPR, the cardiac output is between 25 and $40 \%$ of pre-arrest values while the coronary arteries receive 5-15\% of this amount [9]. During the relaxation phase of CPR, CPP (the difference between DAP and right atrial pressure - RAP) is generated as blood passively flows from the aorta into the coronary arteries. The peak systolic arterial pressure ranges between 60 and $80 \mathrm{mmHg}$, while the mean pulmonary artery pressure is approximately $40 \mathrm{mmHg}$. This, together with the hypoxic pulmonary vasoconstriction, may increase RAP and aggravates venous return and CPP. Even though the coronary blood flow may be low and cannot maintain aerobic myocardial metabolism, it may be sufficient enough to promote the deleterious effects of reperfusion, which has been initiated by the onset of CPR.

In the brain, blood flow is partially restored by the onset of CPR. During optimal chest compressions, the brain receives $30 \%$ of the compression-related cardiac output [10]. During the compression phase, ICP is increased probably due to changes in intrathoracic pressure transduced through the paravertebral venous/epidural plexus and spinal fluid to the intracranial compartment, which in turn increases resistance to cerebral perfusion $[11,12]$. On the contrary, ICP decreases during chest recoil based on the same pressure mechanisms that increase ICP during the compression phase [13]. In addition, the activation of blood coagulation after the onset of reperfusion leads to the formation of microthrombi, while the activated neutrophils and platelets accumulate in microvessels [10]. These impair cerebral microvascular blood flow which may further be compromised by the $\alpha 1$-adrenergic agonist action of endogenous and/or exogenous adrenaline which reduces capillary blood flow and increases arterial lactate levels.

Despite the significant research efforts during the last decades, the physiology of cardiac arrest and resuscitation remains only partially understood. Although much discussion takes place worldwide regarding the mechanisms of blood flow during CPR, it is widely recognized that increased emphasis should be given on the optimal performance of chest compressions. The mechanism of blood flow during CPR seems to be dependent on the stage and momentum of compression or decompression, without forgetting that the effect of ventilation, as well as that of compression force and rate, may vary during CPR [6, 14]. However, chest compression depth has been inversely associated with survival, while the depth necessary to generate forward blood flow is not uniform between individuals [5]. Therefore, compression depth should be actively titrated to a targeted physiologic arterial blood pressure goal in highly monitored patients.

The effectiveness of chest compressions is also dependent on venous return, which is proportional to the pressure gradient between Pmsf and central venous pressure (CVP). If chest compression rate and depth remain within currently recommended limits, venous return will be mainly maintained by the pressure gradient between Pmsf and CVP [15]. As the systemic vascular resistance is highly affected by the patient's condition and previous administration of anesthetic agents, it is extremely important to preserve Pmsf, especially in mechanically ventilated patients with cardiac arrest. Considering that the venous system has a large vascular capacitance and a constant compliance, large fluid volume infusion may rapidly increase right filling pressures while exerting a minimal effect on Pmsf, thus diminishing venous return, especially if administered via a subclavian or internal jugular vein. At the same time, fluid infusion is important for increasing systemic pressures and tissue perfusion. 
Therefore, optimization of venous return is crucial in order to increase the compression-related cardiac output and in this context, vigilant ventilation and fluid administration, as well as earlier small doses of vasopressors, could optimize Pmsf and venous return.

\section{Improving microcirculatory blood flow}

At the microcirculatory level, arterioles are richly adrenergically innervated, thus responding to adrenergic stimulation causing vasoconstriction. Following sympathetic stimulation, the $\mathrm{A} 1$ and $\mathrm{A} 2$ arterioles show the greatest percentage of change in diameter values and remain constricted for long periods of time, whereas the A3 and A4 arterioles respond initially via constriction, but return to their initial diameter in a short period of time [16]. Vasodilatation of the smallest distal arterioles may assist with the maintenance of adequate tissue perfusion when larger arterioles are constricted.

During CPR, arterial blood pressure may correlate only poorly with microcirculatory flow and normalization or elevating blood pressure with vasopressors may result in unpredictable effects on microcirculatory and capillary perfusion, despite reaching initial resuscitation endpoints, such as DAP and/or $\mathrm{ETCO}_{2}[17,18]$. As prolonged resuscitation leads to accrual of ischemic injury and results in ischemic contracture of the heart that inevitably becomes unresponsive to defibrillation and resuscitation efforts [9], a CPR method that provides higher tissue perfusion may lead to better outcomes by delaying ischemic cardiac contracture and decreasing neurological injury.

Nitroglycerin has a favorable hemodynamic profile which promotes forward blood flow and has been associated with increased rates of resuscitation and improved postresuscitation outcome [19]. It can diffuse through all membranes, including the blood-brain barrier, and it is a potent cerebrovasodilator that increases cerebral blood flow through the release of nitric oxide (NO) from the endothelium [20]. Nitroglycerin also improves the endothelial function and the vascular tone of cerebral vessels and inhibits platelet aggregation and neutrophil adhesion simultaneously, improving macro- and microcirculatory blood flow and ameliorating ischemic damage [21, 22]. In addition to the primarily vascular activity, it may also have antioxidant effects through the release of NO, which is a potent antioxidant and is capable of rendering neuroprotection against oxidative stress-induced neurotoxicity [23]. Besides nitroglycerin, sodium nitroprusside-enhanced CPR has been shown to improve myocardial, carotid, and cerebral blood flow, postresuscitation left ventricular global function, and 24-h survival with good neurological function in porcine models of cardiac arrest $[24,25]$. Also, the addition of inhaled NO to hemodynamic-directed CPR may improve short-term survival and intra-arrest hemodynamics [26].

\section{Ventilation during cardiopulmonary resuscitation}

\section{Tracheal intubation and mechanical ventilation}

Although it is widely believed that positive-pressure ventilation during CPR is bad for the circulation, proper timing of compression and ventilation may actually improve the circulation. Indeed, increasing evidence from large cohorts and a meta-analysis suggest that early insertion of endotracheal tube and positive-pressure ventilation may increase immediate survival [27-29]. During positivepressure ventilation, blood flow may be promoted by the "thoracic pump," but by the beginning of the expiratory phase (ventilator pause), the "thoracic pump" effect decreases as the "cardiac pump" begins to take over, reaching a peak effect by the end of ventilator pause and just before the inspiratory phase [6].

Of note, ventilation during CPR by using currently recommended chest compression rates has been reported to take place entirely below functional residual capacity and is associated with negative intrathoracic pressures during decompression [30], while the severe lung de-recruitment and atelectasis observed in chest compression-only CPR are not expected in mechanical ventilated patients in whom sufficient ventilation has preceded the onset of cardiac arrest, even with low pressures [14]. Consequently, each positive-pressure breath inflates the lungs, facilitates $\mathrm{O}_{2}$ delivery, and opens up the pulmonary arterial and venous vasculature, allowing for respiration and transpulmonary circulation $[13,14,30,31]$. However, a positive-pressure breath increases intrathoracic pressure, which may decrease right ventricular preload while increasing right ventricular afterload and ICP, thereby decreasing cerebral perfusion pressure (CerPP) [13]. Therefore, achieving the correct balance between too little and too much ventilation is of major importance for optimizing survival, and there must be an intrathoracic pressure limit for each patient at which the effect of "thoracic pump" should be maximal. Above this limit, intrathoracic pressure would be deleterious, while under this limit, ventilation may not provide adequate blood oxygenation due to small airway closure, increasing pulmonary vascular resistance and impairing gas exchange $[6,14,31]$. Our group has recently showed an association between mean airway pressure and outcome of CPR in mechanically ventilated patients, with a value of 42.5 mbar being associated with return of spontaneous circulation (ROSC) [14]. Ventilatory parameters were intermitted positive-pressure ventilation mode, tidal volume $6 \mathrm{ml} / \mathrm{kg}$, respiratory rate $10 \mathrm{~min}^{-1}$, I:E 1:2, PEEP $0 \mathrm{~cm} \mathrm{H}_{2} 0$, and fraction of inspired oxygen $\left(\mathrm{FiO}_{2}\right) 100 \%$. In this study, we found no 
difference in $\mathrm{ETCO}_{2}$ between survivors and non-survivors probably due to the maintenance of flow in small airways and the improvement in minute-volume ventilation during CPR [30-32].

\section{How much oxygen during cardiopulmonary resuscitation?}

Although current guidelines recommend giving the maximum feasible inspired oxygen during CPR [1], the optimal oxygen requirement remains uncertain, as too little or too much could be harmful. Considering that ROSC may be more likely with high $\mathrm{FiO}_{2}$, as well as it may not result in cerebral hyperoxia, it seems prudent to continue to provide $100 \%$ oxygen during CPR or maintaining an arterial oxygen saturation of $>94 \%$ in patient with hemoglobin $(\mathrm{Hb})$ levels of $>10 \mathrm{~g} / \mathrm{dl}$ and a central venous oxygen saturation $\left(\mathrm{ScvO}_{2}\right)$ of $65-80 \%$.

\section{Capnography and end-tidal carbon dioxide}

During $\mathrm{CPR}$, changes in $\mathrm{ETCO}_{2}$ parallel the changes in pulmonary blood flow and thus cardiac output, provided that other factors that regulate $\mathrm{ETCO}_{2}$ are constant [33]. Taking into consideration that blood flow and CPP during CPR depend on the quality of chest compressions [34], capnography and $\mathrm{ETCO}_{2}$ monitoring can be a valuable asset, serving as an indicator of systemic and pulmonary blood flow and reflecting the effects of CPR on cardiac output and stroke volume index [33].

On the other hand, it should be noted that many potential confounding factors may affect the levels of $\mathrm{ETCO}_{2}$, such as the cause of the arrest, hypercapnia, the initial heart rhythm, the early onset of CPR, the rescuer fatigue, and the administration of epinephrine, sodium bicarbonate, or other drugs [33, $35,36]$. In mechanically ventilated patients, the simultaneous positive-pressure ventilation in time with each chest compression may prevent a loss of intrathoracic pressure via the airway and maintain air flow in small airways, improving minute-volume ventilation and maintaining stable or even reducing $\mathrm{ETCO}_{2}$ [31-33]. Therefore, low or decreasing $\mathrm{ETCO}_{2}$ levels during $\mathrm{CPR}$ may not necessarily indicate poor prognosis in mechanically ventilated patients.

\section{Neuroprotection during cardiopulmonary resuscitation: brain tissue oxygen saturation}

Maintaining sufficient cerebral perfusion during CPR is strongly associated with survival and favorable neurologic outcome in animals [37-39], and cerebral oximetry is a noninvasive technology that uses near-infrared light to measure brain tissue perfusion $[40,41]$. Until now, however, no general threshold has been set at which ROSC will be achieved. In a study of in-hospital cardiac arrest, patients with sustained
ROSC had higher overall brain tissue oxygen saturation $\left(\mathrm{rSO}_{2}\right)$ during CPR, while patients who survived to hospital discharge with a favorable neurologic outcome had higher $\mathrm{rSO}_{2}$ than those who did not survive to hospital discharge [42]. Also, an $\mathrm{rSO}_{2}$ values less than $30 \%$ has been negatively correlated with ROSC $[8,41,43]$. Furthermore, there is evidence that $\mathrm{rSO}_{2}$ can play a role in predicting neurologic outcome 1 week after cardiac arrest or at hospital discharge [41].

Considering that cerebral perfusion during CPR is critical for neurologically intact survival, enhancing cerebral vein drainage will lead to decreased ICP thereby promoting forward cerebral flow. Interestingly, it has been reported that an increase in intrathoracic pressure may not reduce internal jugular vein drainage, but actually it may increase intracranial venous volume in healthy individuals in the upright posture [44]. As the decompression-induced negative intrathoracic pressure is not affected by ventilation, optimizing intrathoracic pressure during incline CPR may allow venous return and enhance cerebral vein drainage and oxygenation $[14,30,45]$. This may be facilitated with the use of Head Up CPR (HUP-CPR), which uses gravity to enhance venous return from the head and paravertebral plexus, further reducing ICP and increasing CerPP [46]. In a swine study, CerPP remained significantly higher in the HUP-CPR pigs, especially when an impedance threshold device was used [47]. These physiological changes were recently replicated in deceased human cadaver models; HUP-CPR resulted in decreased ICP and increased CerPP, further supporting its use in patients in cardiac arrest [48]. Nevertheless, the compression-related cardiac output may be impaired during human HUP-CPR due to pooling of blood in the lower extremities.

\section{Blood pressure-directed cardiopulmonary resuscitation versus end-tidal carbon dioxide-directed cardiopulmonary resuscitation}

Until now, numerous randomized-controlled animal studies have established that hemodynamic-directed targeted CPR results in superior outcomes compared to standard CPR [8], while animal data regarding $\mathrm{ETCO}_{2}$-directed $\mathrm{CPR}$ are not as convincing $[49,50]$. Mean DAP $>34 \mathrm{mmHg}$ was reported to be a superior discriminator of survival than mean $\mathrm{ETCO}_{2}$ in porcine models of in-hospital cardiac arrest [5]. In this study, DAP values during the final 2 min of CPR preceding the first defibrillation attempt were substantially higher among survivors compared with non-survivors, but the concomitant $\mathrm{ETCO}_{2}$ measurements did not differ between survivors and non-survivors.

As stated before, a number of factors may influence $\mathrm{ETCO}_{2}$, including minute ventilation, pulmonary pathology, and the ventilation/perfusion defects that occur with 
vasopressor administration [5]. It is important to remember that $\mathrm{ETCO}_{2}$ primarily reflects pulmonary blood flow rather than myocardial blood flow, while cardiac output does not always correlate with DAP and its downstream effects on myocardial blood flow. Of note, the main determinant of Pmsf, venous return, and DAP adequacy (and therefore myocardial flow) is systemic vascular resistance [5].

Targeting intra-arrest hemodynamics compared to standard CPR has been reported to improve both short- and long-term survival with favorable neurologic outcomes [5, 51, 52]. Besides the evidence, it can be easily understood that inability to obtain an adequate DAP is highly predictive of death and patient-centric titration of CPR to hemodynamics may improve survival rates.

\section{The PERSEUS personalized physiology-guided resuscitation protocol}

Recognizing cardiac arrest in highly monitored areas can be more difficult than in other hospital areas, such as the ward. Considering that the vast majority of alarms from sensors are false alarms [53], cardiac arrest should be recognized and confirmed by the combined assessment of the rhythm, the arterial blood pressure and waveform, the abrupt decrease of $\mathrm{ETCO}_{2}$, and the loss of carotid pulse. Once cardiac arrest is confirmed, CPR should be initiated without delay with highquality chest compressions according to the recent resuscitation guidelines (Fig. 1) [1]. However, the effectiveness of chest compressions is depending on the venous return, which

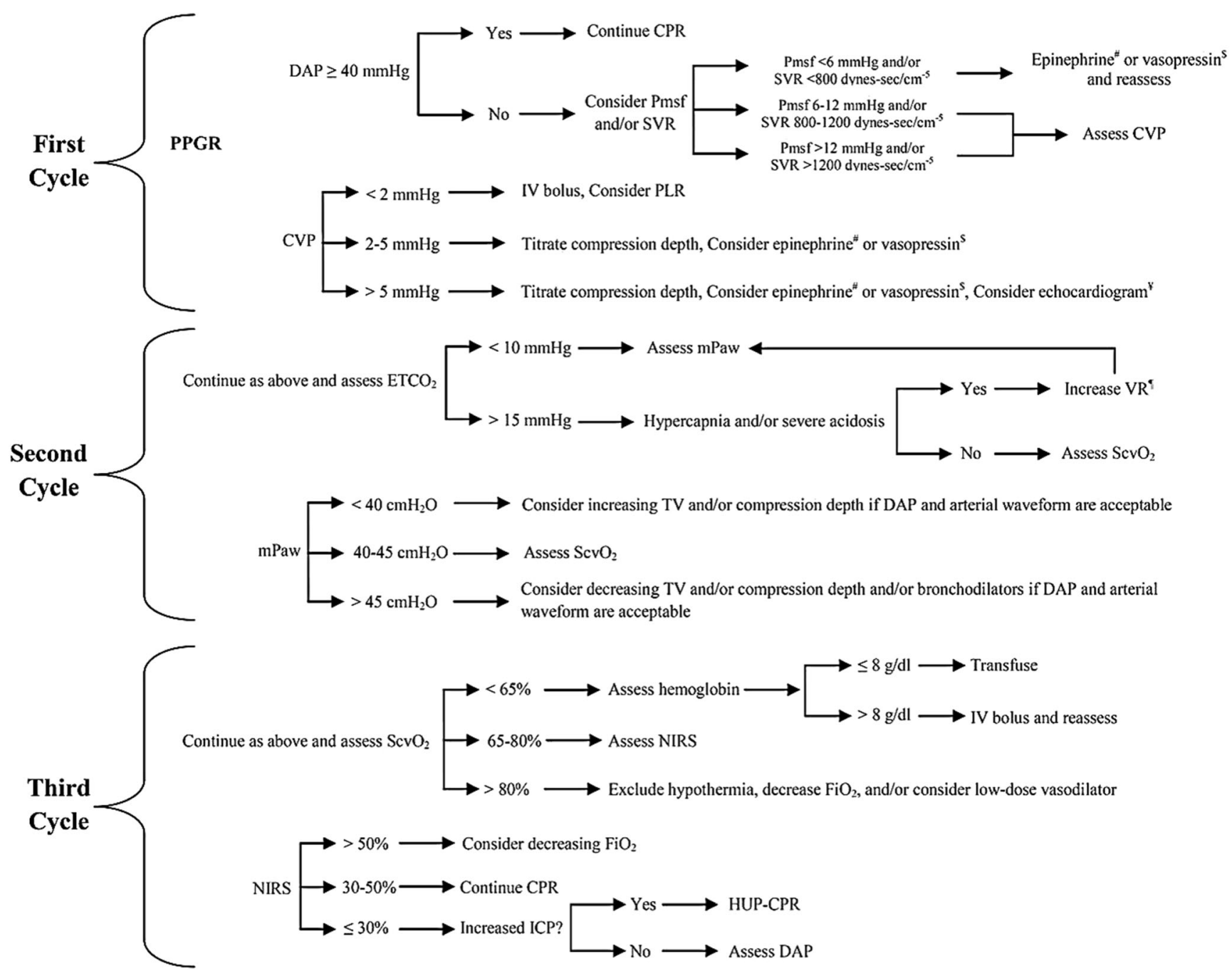

Fig. 1 Our stepwise approach to the management of cardiac arrest in highly monitored patients. PPGR, personalized physiology-guided resuscitation; CPR, cardiopulmonary resuscitation; DAP, diastolic arterial pressure; Pmsf, mean systemic filling pressure; SVR, systemic vascular resistance; CVP, central venous pressure, PLR, passive leg raising; $\mathrm{ETCO}_{2}$, end-tidal carbon dioxide; mPaw, mean airway pressure; VR, ventilation rate; $\mathrm{ScvO}_{2}$, central venous oxygen saturation; TV, tidal volume; NIRS, near-infrared spectroscopy; $\mathrm{FiO}_{2}$, fraction of inspired oxygen; ICP, intracranial pressure; HUP-CPR, head up cardiopulmonary resuscitation at $30^{\circ}$. " Epinephrine $100-1000 \mathrm{mcg}$ IV, may repeat/ consider epinephrine infusion. ${ }^{\$}$ May replace 1 dose of epinephrine with 4-40 U of Vasopressin IV. ${ }^{¥}$ Consider inhaled nitric oxide in known or suspected increased pulmonary hypertension. ${ }^{\text {II }} \mathrm{Up}$ to $50 \%$ or less if necessary to maintain DAP $\geq 40 \mathrm{mmHg}$ 
is proportional to the pressure gradient between Pmsf and CVP, and particular attention is needed by the rescuers to determine Pmsf within the first 5-7.5 s of cardiac arrest and prior to the onset of chest compressions [54, 55]. The Pmsf is a quantitative measurement of the patient's volume status and represents the tone of venous reservoir [56], indicating the pre-arrest "vasoreactivity" status of the patients. Therefore, optimizing Pmsf during CPR is paramount for increasing survival rates.

During the first cycle of CPR, the resuscitation efforts must maintain a relaxation DAP of $\geq 40 \mathrm{mmHg}$ (calculated at the time of full chest decompression) [3-5]. In patients with a lower DAP, administration of epinephrine or vasopressin should be based on the pre-arrest value of Pmsf and/or systemic vascular resistance (SVR) and is anticipated to be beneficial in those with Pmsf $<6 \mathrm{mmHg}$ and/or SVR $<800$ dynes-sec $/ \mathrm{cm}^{-5}$, enhancing volume recruitment from the unstressed compartment and increasing the stressed volume [57-59]. In all other patients, the vasoreactivity will be maintained for some time provided that intravascular volume and chest compressions are sufficient. Therefore, circulatory volume should be increased in patients with a pre-arrest CVP $<$ $2 \mathrm{mmHg}$ using a fluid bolus and/or the passive leg-raising maneuver. However, it should be noted that rapid and liberal fluid administration during CPR may lead to an excessive increase in RAP, aggravating venous return and CPP, especially when administered via a jugular or subclavian central venous catheter. At the onset of cardiac arrest, ventilatory parameters should be changed to tidal volume $6 \mathrm{ml} / \mathrm{kg}$, respiratory rate $10 \mathrm{~min}^{-1}$, I:E $1: 2$, PEEP $0 \mathrm{~cm} \mathrm{H}_{2} 0$, and $\mathrm{FiO}_{2} 100 \%$ $[1,14]$. During this cycle, all other treatment efforts must follow current recommendations for standard CPR [1].

After the onset of the second cycle of CPR, the resuscitation efforts should be continued as above while assessing $\mathrm{ETCO}_{2}$. As stated previously, ventilation during CPR by using currently recommended chest compression rates may take place entirely below functional residual capacity and may not provide adequate blood oxygenation due to small airway closure, increasing pulmonary vascular resistance and impairing gas exchange $[6,14,30,31]$. Therefore, mean airway pressure should be maintained $40-45 \mathrm{cmH}_{2} \mathrm{O}$ in patients with DAP $\geq 40 \mathrm{mmHg}$ and $\mathrm{ETCO}_{2}<10 \mathrm{mmHg}$ to facilitate gas exchange. On the contrary, all patients with DAP $>$ $40 \mathrm{mmHg}$ and $\mathrm{ETCO}_{2}>15 \mathrm{mmHg}$ should be assessed for hypercapnia, and if present, they should be treated by increasing the ventilatory rate by up to $50 \%$ (or less if necessary to maintain DAP $\geq 40 \mathrm{mmHg}$ ). Also, severe acidosis should be treated immediately because it causes vasodilatation which may decrease venous return and CPP.

During the third cycle of CPR, the resuscitation efforts should be continued as above while assessing $\mathrm{ScvO}_{2}$, which should be maintained 65-80\%. In patients with $\mathrm{ScvO}_{2}<65 \%$, transfusion of red blood cells should be initiated when $\mathrm{Hb}$ is $\leq 8 \mathrm{~g} / \mathrm{dl}$ to improve oxygen delivery. In patients with $\mathrm{Hb}>8 \mathrm{~g} / \mathrm{dl}$, a fluid bolus should be given to improve circulatory flow provided that DAP is maintained $\geq 40 \mathrm{mmHg}$. In patients with DAP $\geq$ $40 \mathrm{mmHg}$ and $\mathrm{ScvO}_{2}$ value of $>80 \%$, hypothermia should be excluded and treated aggressively if present, the $\mathrm{FiO}_{2}$ should be decreased in case of hyperoxemia $\left(\mathrm{PaO}_{2}>200 \mathrm{mmHg}\right)$, and a low-dose vasodilator may be considered when microcirculatory shunting and loss of hemodynamic coherence between macroand microcirculation can be directly assessed or possible (e.g., DAP $\geq 40 \mathrm{mmHg}, \mathrm{Hb}>8 \mathrm{~g} / \mathrm{dl}, \mathrm{PaO}_{2}>200 \mathrm{mmHg}$, $\mathrm{ScvO}_{2}>80 \%$, and mixed venous oxygen tension $\leq 26 \mathrm{mmHg}$ (if available), with or without hyperlactatemia). In patients with normal $\mathrm{ScvO}_{2}$, trend cerebral oxygenation monitoring (near-infrared spectroscopy - NIRS) should be used because it focuses more on the amount of change from the pre-arrest baseline cerebral oxygenation value. Decreasing $\mathrm{FiO}_{2}$ until $\mathrm{PaO}_{2}$ is $200 \mathrm{mmHg}$ can be considered when NIRS is $>50 \%$ of the prearrest value, while HUP-CPR $\left(30^{\circ}\right)$ should be considered in patients with NIRS $\leq 30 \%$ of the pre-arrest value and signs or known increased intracranial pressure. The resuscitation efforts may be considered as adequate in patients who have reached the pre-defined targets and have a NIRS of 30-50\% of the pre-arrest value, and should be continued by repeating the approach from the beginning. Finally, extracorporeal CPR should be considered after 8-10 cycles of CPR.

\section{Conclusion}

Although outcomes after cardiac arrest remain poor more than 50 years, increasing evidence suggest that physiology-guided resuscitation may increase both short- and long-term survival. The PERSEUS CPR is a new approach to the resuscitation of highly monitored patients with cardiac arrest and could serve as a treatment strategy to titrate chest compressions, ventilation, and vasopressor dosing to physiological parameters.

\section{Compliance with ethical standards}

Conflict of interest The authors declare that they have no conflict of interest.

Publisher's note Springer Nature remains neutral with regard to jurisdictional claims in published maps and institutional affiliations.

\section{References}

1. Soar J, Nolan JP, Böttiger BW, Perkins GD, Lott C, Carli P, Pellis T, Sandroni C, Skrifvars MB, Smith GB, Sunde K, Deakin CD, Adult advanced life support section Collaborators (2015) European Resuscitation Council Guidelines for Resuscitation 2015: Section 3. Adult advanced life support. Resuscitation 95:100-147

2. Meaney PA, Bobrow BJ, Mancini ME, Christenson J, de Caen AR, Bhanji F, Abella BS, Kleinman ME, Edelson DP, Berg RA, 
Aufderheide TP, Menon V, Leary M, CPR Quality Summit Investigators, the American Heart Association Emergency Cardiovascular Care Committee, and the Council on Cardiopulmonary, Critical Care, Perioperative and Resuscitation (2013) Cardiopulmonary resuscitation quality: [corrected] improving cardiac resuscitation outcomes both inside and outside the hospital: a consensus statement from the American Heart Association. Circulation 128:417-435

3. Sutton RM, Friess SH, Maltese MR, Naim MY, Bratinov G, Weiland TR, Garuccio M, Bhalala U, Nadkarni VM, Becker LB, Berg RA (2014) Hemodynamic-directed cardiopulmonary resuscitation during in-hospital cardiac arrest. Resuscitation 85:983-986

4. Chopra AS, Wong N, Ziegler CP, Morrison LJ (2016) Systematic review and meta-analysis of hemodynamic-directed feedback during cardiopulmonary resuscitation in cardiac arrest. Resuscitation 101:102-107

5. Morgan RW, French B, Kilbaugh TJ, Naim MY, Wolfe H, Bratinov G, Shoap W, Hsieh TC, Nadkarni VM, Berg RA, Sutton RM (2016) A quantitative comparison of physiologic indicators of cardiopulmonary resuscitation quality: diastolic blood pressure versus endtidal carbon dioxide. Resuscitation 104:6-11

6. Chalkias A, Xanthos T (2015) Timing positive-pressure ventilation during chest compression: the key to improving the thoracic pump? Eur Heart J Acute Cardiovasc Care 4:24-27

7. Chalkias A, Spyropoulos V, Koutsovasilis A, Papalois A, Kouskouni E, Xanthos T (2015) Cardiopulmonary arrest and resuscitation in severe sepsis and septic shock: a research model. Shock 43:285-291

8. Marquez AM, Morgan RW, Ross CE, Berg RA, Sutton RM (2018) Physiology-directed cardiopulmonary resuscitation: advances in precision monitoring during cardiac arrest. Curr Opin Crit Care 24:143-150

9. Chalkias A, Xanthos T (2012) Pathophysiology and pathogenesis of post-resuscitation myocardial stunning. Heart Fail Rev 17:117128

10. Chalkias A, Xanthos T (2012) Post-cardiac arrest brain injury: pathophysiology and treatment. J Neurol Sci 315:1-8

11. Metzger AK, Herman M, McKnite S, Tang W, Yannopoulos D (2012) Improved cerebral perfusion pressures and 24-hr neurological survival in a porcine model of cardiac arrest with active compression-decompression cardiopulmonary resuscitation and augmentation of negative intrathoracic pressure. Crit Care Med 40:1851-1856

12. Debaty G, Shin SD, Metzger A, Kim T, Ryu HH, Rees J, McKnite S, Matsuura T, Lick M, Yannopoulos D, Lurie K (2015) Tilting for perfusion: head-up position during cardiopulmonary resuscitation improves brain flow in a porcine model of cardiac arrest. Resuscitation 87:38-43

13. Lurie KG, Nemergut EC, Yannopoulos D, Sweeney M (2016) The physiology of cardiopulmonary resuscitation. Anesth Analg 122: 767-783

14. Chalkias A, Pavlopoulos F, Koutsovasilis A, d'Aloja E, Xanthos T (2017) Airway pressure and outcome of out-of-hospital cardiac arrest: a prospective observational study. Resuscitation 110:101106

15. Guyton AC, Hall JE (2000) Cardiac output, venous return, and their regulation. In: Schmitt W, Gruliow RWB (eds) Textbook of medical physiology, 10th edn. Saunders Company, Philadelphia, pp 210222

16. Marshall JM (1982) The influence of the sympathetic nervous system on individual vessels of the microcirculation of skeletal muscle of the rat. J Physiol 332:169-186

17. Krupičková $\mathrm{P}$, Mlček M, Huptych M, Mormanová Z, Bouček T, Belza T, Lacko S, Černý M, Neužil P, Kittnar O, Linhart A, Bělohlávek J (2016) Microcirculatory blood flow during cardiac arrest and cardiopulmonary resuscitation does not correlate with global hemodynamics: an experimental study. J Transl Med 14:163

18. Krupičková P, Mormanová Z, Bouček T, Belza T, Šmalcová J, Bělohlávek J (2018) Microvascular perfusion in cardiac arrest: a review of microcirculatory imaging studies. Perfusion 33:8-15

19. Stefaniotou A, Varvarousi G, Varvarousis DP, Xanthos T (2014) The effects of nitroglycerin during cardiopulmonary resuscitation. Eur J Pharmacol 734:42-49

20. Nishida T, Yu JD, Minamishima S, Sips PY, Searles RJ, Buys ES, Janssens S, Brouckaert P, Bloch KD, Ichinose F (2009) Protective effects of nitric oxide synthase 3 and soluble guanylate cyclase on the outcome of cardiac arrest and cardiopulmonary resuscitation in mice. Crit Care Med 37:256-262

21. Radomski MW, Palmer RM, Moncada S (1991) Modulation of platelet aggregation by an L-arginine-nitric oxide pathway. Trends Pharmacol Sci 12:87-88

22. Mohanakumar KP, Thomas B, Sharma SM, Muralikrishnan D, Chowdhury R, Chiueh CC (2002) Nitric oxide: an antioxidant and neuroprotector. Ann N Y Acad Sci 962:389-401

23. Nicolescu AC, Zavorin SI, Turro NJ, Reynolds JN, Thatcher GR (2002) Inhibition of lipid peroxidation in synaptosomes and liposomes by nitrates and nitrites. Chem Res Toxicol 15:985-998

24. Debaty G, Metzger A, Rees J, McKnite S, Puertas L, Yannopoulos D, Lurie K (2015) Enhanced perfusion during advanced life support improves survival with favorable neurologic function in a porcine model of refractory cardiac arrest. Crit Care Med 43:1087-1095

25. Yannopoulos D, Bartos JA, George SA, Sideris G, Voicu S, Oestreich B, Matsuura T, Shekar K, Rees J, Aufderheide TP (2017) Sodium nitroprusside enhanced cardiopulmonary resuscitation improves short term survival in a porcine model of ischemic refractory ventricular fibrillation. Resuscitation 110:6-11

26. Morgan RW, Sutton RM, Karlsson M, Lautz AJ, Mavroudis CD, Landis WP, Lin Y, Jeong S, Craig N, Nadkarni VM, Kilbaugh TJ, Berg RA (2018) Pulmonary vasodilator therapy in shock-associated cardiac arrest. Am J Respir Crit Care Med 197:905-912

27. Kang K, Kim T, Ro YS, Kim YJ, Song KJ, Shin SD (2016) Prehospital endotracheal intubation and survival after out-ofhospital cardiac arrest: results from the Korean nationwide registry. Am J Emerg Med 34:128-132

28. Wang CH, Chen WJ, Chang WT, Tsai MS, Yu PH, Wu YW, Huang $\mathrm{CH}$ (2016) The association between timing of tracheal intubation and outcomes of adult in-hospital cardiac arrest: a retrospective cohort study. Resuscitation 105:59-65

29. Benoit JL, Gerecht RB, Steuerwald MT, McMullan JT (2015) Endotracheal intubation versus supraglottic airway placement in out-of-hospital cardiac arrest: a meta-analysis. Resuscitation 93: $20-26$

30. Cordioli RL, Lyazidi A, Rey N, Granier JM, Savary D, Brochard L, Richard JC (2016) Impact of ventilation strategies during chest compression: an experimental study with clinical observations. J Appl Physiol (1985) 120:196-203

31. Grieco DL, Brochard L, Drouet A, Telias I, Delisle S, Bronchti G, Ricard C, Rigollot M, Badat B, Ouellet P, Charbonney E, Mancebo J, Mercat A, Savary D, Richard JM, CAVIAR Group (2018) Intrathoracic airway closure impacts $\mathrm{CO}_{2}$ signal and delivered ventilation during cardiopulmonary resuscitation. Am J Respir Crit Care Med. https://doi.org/10.1164/rccm.201806-1111OC [Epub ahead of print]

32. Gazmuri RJ, Ayoub IM, Radhakrishnan J, Motl J, Upadhyaya MP (2012) Clinically plausible hyperventilation does not exert adverse hemodynamic effects during CPR but markedly reduces end-tidal $\mathrm{PCO}_{2}$. Resuscitation 83:259-264

33. Pantazopoulos C, Xanthos T, Pantazopoulos I, Papalois A, Kouskouni E, Iacovidou N (2015) A review of carbon dioxide monitoring during adult cardiopulmonary resuscitation. Heart Lung Circ 24:1053-1061 
34. Steen S, Liao Q, Pierre L, Paskevicius A, Sjöberg T (2003) The critical importance of minimal delay between chest compressions and subsequent defibrillation: a haemodynamic explanation. Resuscitation 58:249-258

35. Varvarousis D, Xanthos T, Ferino G, Noto A, Iacovidou N, Mura M, Scano P, Chalkias A, Papalois A, De-Giorgio F, Baldi A, Mura P, Staikou C, Stocchero M, Finco G, d'Aloja E, Locci E (2017) Metabolomics profiling reveals different patterns in an animal model of asphyxial and dysrhythmic cardiac arrest. Sci Rep 7:16575

36. Sandroni C, De Santis P, D’Arrigo S (2018) Capnography during cardiac arrest. Resuscitation 132:73-77

37. Bouček T, Mlček M, Krupičková P, Huptych M, Belza T, Kittnar O, Linhart A, Bělohlávek J (2018) Brain perfusion evaluated by regional tissue oxygenation as a possible quality indicator of ongoing cardiopulmonary resuscitation. An experimental porcine cardiac arrest study. Perfusion 33:65-70

38. Putzer G, Braun P, Strapazzon G, Toferer M, Mulino M, Glodny B, Falk M, Brugger H, Paal P, Helbok R, Mair P (2016) Monitoring of brain oxygenation during hypothermic $\mathrm{CPR}$ - a prospective porcine study. Resuscitation 104:1-5

39. Schnaubelt S, Sulzgruber P, Menger J, Skhirtladze-Dworschak K, Sterz F, Dworschak M (2018) Regional cerebral oxygen saturation during cardiopulmonary resuscitation as a predictor of return of spontaneous circulation and favourable neurological outcome - a review of the current literature. Resuscitation 125:39-47

40. Ibrahim AW, Trammell AR, Austin H, Barbour K, Onuorah E, House D, Miller HL, Tutt C, Combs D, Phillips R, Dickert NW, Zafari AM (2015) Cerebral oximetry as a real-time monitoring tool to assess quality of in-hospital cardiopulmonary resuscitation and post cardiac arrest care. J Am Heart Assoc 4:e001859

41. Genbrugge C, Dens J, Meex I, Boer W, Eertmans W, Sabbe M, Jans F, De Deyne C (2016) Regional cerebral oximetry during cardiopulmonary resuscitation: useful or useless? J Emerg Med 50:198207

42. Parnia S, Yang J, Nguyen R, Ahn A, Zhu J, Inigo-Santiago L, Nasir A, Golder K, Ravishankar S, Bartlett P, Xu J, Pogson D, Cooke S, Walker C, Spearpoint K, Kitson D, Melody T, Chilwan M, Schoenfeld E, Richman P, Mills B, Wichtendahl N, Nolan J, Singer A, Brett S, Perkins GD, Deakin CD (2016) Cerebral oximetry during cardiac arrest: a multicenter study of neurologic outcomes and survival. Crit Care Med 44:1663-1674

43. Cournoyer A, Iseppon M, Chauny JM, Denault A, Cossette S, Notebaert É (2016) Near-infrared spectroscopy monitoring during cardiac arrest: a systematic review and meta-analysis. Acad Emerg Med 23:851-862

44. Yeoh TY, Venkatraghavan L, Fisher JA, Meineri M (2017) Internal jugular vein blood flow in the upright position during external compression and increased central venous pressure: an ultrasound study in healthy volunteers. Can J Anaesth 64:854-859

45. Friess SH, Sutton RM, French B, Bhalala U, Maltese MR, Naim MY, Bratinov G, Arciniegas Rodriguez S, Weiland TR, Garuccio M, Nadkarni VM, Becker LB, Berg RA (2014) Hemodynamic directed CPR improves cerebral perfusion pressure and brain tissue oxygenation. Resuscitation 85:1298-1303
46. Moore JC, Bartos JA, Matsuura TR, Yannopoulos D (2017) The future is now: neuroprotection during cardiopulmonary resuscitation. Curr Opin Crit Care 23:215-222

47. Ryu HH, Moore JC, Yannopoulos D, Lick M, McKnite S, Shin SD, Kim TY, Metzger A, Rees J, Tsangaris A, Debaty G, Lurie KG (2016) The effect of head up cardiopulmonary resuscitation on cerebral and systemic hemodynamics. Resuscitation 102:29-34

48. Moore JC, Holley J, Segal N, Lick MC, Labarère J, Frascone RJ, Dodd KW, Robinson AE, Lick C, Klein L, Ashton A, McArthur A, Tsangaris A, Makaretz A, Makaretz M, Debaty G, Pepe PE, Lurie KG (2018) Consistent head up cardiopulmonary resuscitation haemodynamics are observed across porcine and human cadaver translational models. Resuscitation 132:133-139

49. Hamrick JL, Hamrick JT, Lee JK, Lee BH, Koehler RC, Shaffner DH (2014) Efficacy of chest compressions directed by end-tidal $\mathrm{CO}_{2}$ feedback in a pediatric resuscitation model of basic life support. J Am Heart Assoc 3:e000450

50. Hamrick JT, Hamrick JL, Bhalala U, Armstrong JS, Lee JH, Kulikowicz E, Lee JK, Kudchadkar SR, Koehler RC, Hunt EA, Shaffner DH (2017) End-tidal $\mathrm{CO}_{2}$-guided chest compression delivery improves survival in a neonatal asphyxial cardiac arrest model. Pediatr Crit Care Med 18:e575-e584

51. Sutton RM, Friess SH, Bhalala U, Maltese MR, Naim MY, Bratinov G, Niles D, Nadkarni VM, Becker LB, Berg RA (2013) Hemodynamic directed CPR improves short-term survival from asphyxia-associated cardiac arrest. Resuscitation 84:696-701

52. Sutton RM, French B, Meaney PA, Topjian AA, Parshuram CS, Edelson DP, Schexnayder S, Abella BS, Merchant RM, Bembea M, Berg RA, Nadkarni VM, American Heart Association's Get With The Guidelines-Resuscitation Investigators (2016) Physiologic monitoring of CPR quality during adult cardiac arrest: a propensity-matched cohort study. Resuscitation 106:76-82

53. Moitra VK, Einav S, Thies KC, Nunnally ME, Gabrielli A, Maccioli GA, Weinberg G, Bannerjee A, Ruetzler K, Dobson G, McEvoy M, O'Connor MF (2018) Cardiac arrest in the operating room: resuscitation and management for the anesthesiologist part 1 . Anesth Analg 127:e49-e50

54. Fessler HE, Brower RG, Wise RA, Permutt S (1991) Effects of positive end-expiratory pressure on the gradient for venous return. Am Rev Respir Dis 143:19-24

55. Jellinek H, Krenn H, Oczenski W, Veit F, Schwarz S, Fitzgerald RD (2000) Influence of positive airway pressure on the pressure gradient for venous return in humans. J Appl Physiol 88:926-932

56. Aya HD, Cecconi M (2015) Can (and should) the venous tone be monitored at the bedside? Curr Opin Crit Care 21:240-244

57. Maas JJ (2015) Mean systemic filling pressure: its measurement and meaning. Netherlands J Crit Care 19:6-11

58. Persichini R, Silva S, Teboul JL, Jozwiak M, Chemla D, Richard C, Monnet X (2012) Effects of norepinephrine on mean systemic pressure and venous return in human septic shock. Crit Care Med 40: 3146-3153

59. Datta P, Magder S (1999) Hemodynamic response to norepinephrine with and without inhibition of nitric oxide synthase in porcine endotoxemia. Am J Respir Crit Care Med 160:1987-1993 